\title{
BMJ Open Isolated oral clefts and school grades: population-based cohort study from Norway
}

Miriam Gjerdevik, ${ }^{1,2}$ Rolv Terje Lie (1) ${ }^{1,2}$ Øystein Ariansen Haaland, ${ }^{2}$ Erik Berg, ${ }^{3}$ Kristin Billaud Feragen, ${ }^{4}$ Åse Sivertsen ${ }^{5}$

To cite: Gjerdevik M, Lie RT, Haaland $\emptyset \mathrm{A}$, et al. Isolated oral clefts and school grades: population-based cohort study from Norway. BMJ Open 2021;11:e046944. doi:10.1136/ bmjopen-2020-046944

- Prepublication history and additional supplemental material for this paper are available online. To view these files, please visit the journal online (http://dx.doi.org/10.1136/ bmjopen-2020-046944).

Received 16 November 2020 Accepted 21 September 2021

Check for updates

(c) Author(s) (or their employer(s)) 2021. Re-use permitted under CC BY-NC. No commercial re-use. See rights and permissions. Published by BMJ.

${ }^{1}$ Centre for Fertility and Health Norwegian Institute of Public Health, Oslo, Norway ${ }^{2}$ Department of Global Public Health and Primary Care, University of Bergen, Bergen, Hordaland, Norway

${ }^{3}$ Department of Plastic and Reconstructive Surgery, Southern Norway Hospital, Arendal, Norway

${ }^{4}$ Centre for Rare Disorders, 0slo University Hospital, Oslo, Norway ${ }^{5}$ Department of Plastic Surgery and Norwegian Quality

Registry of Cleft Lip and Palate, Haukeland University Hospital, Bergen, Norway

Correspondence to

Dr Rolv Terje Lie;

Rolv.Lie@uib.no

\section{ABSTRACT}

Objective To compare school grades of adolescents in Norway born with isolated cleft with those of their unaffected peers.

Design Population-based cohort study.

Setting Norway.

Patients A total of 347419 individuals born in Norway between 1986 and 1992, including 523 isolated cleft cases which were identified using data from Norway's two treatment centres. Individuals were followed from birth through compulsory school.

Main outcome measures Grade point average (GPA) from middle school graduation (around the age of 16). Specific subject grades were also investigated.

Results Using a grade scale from 1-6, the observed mean GPA for the reference group was 3.99. Both cleft lip only (CLO) and cleft lip with cleft palate (CLP) had a mean GPA similar to the reference group (adjusted GPA differences from the reference with $95 \% \mathrm{Cls}$ of 0.06 $(-0.04$ to 0.16$)$ and -0.08 ( -0.19 to 0.03$)$, respectively). Cleft palate only (CP0) had a marginally lower GPA (adjusted GPA difference: $-0.18(-0.28$ to -0.08$)$ ). These comparisons were consistent across specific subjects. Overall, the evidence suggests a larger difference in GPA between cases and controls in males compared with females. Females with CLO even had a higher estimated GPA than females in the reference group (adjusted GPA difference: 0.19 (0.013 to 0.36)). Grades were similar regardless of laterality of cleft lip (CL0 or CLP).

Conclusion In Norway, individuals born with isolated CLO or CLP did not have lower average school grades when graduating from middle school. Individuals born with isolated CPO had marginally lower grades.

\section{INTRODUCTION}

Oral clefts affect 1 in 700 livebirths worldwide $^{1}$ and are broadly categorised by whether the cleft lip only (CLO), the cleft palate only (CPO) or both lip and cleft palate (CLP) are affected. The occurrence of clefts is highly associated with the occurrence of other congenital anomalies, including a wide spectrum of diagnoses with functional implications. ${ }^{2}$ Since the presence of accompanying conditions may be crucial for both aetiology and clinical

\section{STRENGTHS AND LIMITATIONS OF THIS STUDY}

$\Rightarrow$ This study covers the entire population of Norway with practically complete follow-up of the cohort through national registries.

$\Rightarrow$ Norway has uniform treatment of children born with oral cleft as well as a uniform educational system.

$\Rightarrow$ This study had extensive data that helped identify isolated cleft cases, which is the target group of this study.

$\Rightarrow$ Still, identification of children with defects may have been incomplete.

$\Rightarrow$ We were not able to adjust for maternal lifestyle factors during pregnancy.

follow-up, research on oral clefts often distinguishes between clefts occurring with accompanying conditions (non-isolated clefts) and clefts occurring without accompanying conditions (isolated clefts).

Education is important for a prosperous life in modern society, and parents of affected children are often concerned for the future educational prospects of their child. ${ }^{3}$ Several studies have reported poor academic attainment in children born with isolated oral cleft compared with their unaffected peers. ${ }^{4-7}$ A longitudinal cohort study from Iowa, tracking children's academic achievement from elementary through high school, showed that children born with oral cleft are at higher risk for persistent, low achievement in school. ${ }^{8}$ Previous research has suggested that lower school performance is more pronounced for females with cleft than males with cleft, ${ }^{69}$ and that children with isolated leftsided cleft lip are more likely to have lower academic attainment than children with isolated right-sided cleft lip. ${ }^{10}$ Comparisons across these studies are, however, hampered by differences in sample size, study recruitment, educational measures, age group of participants, adjustment for 
potential confounder variables and insufficient exclusion of non-isolated clefts. ${ }^{4}$

A Norwegian study found that, compared with their unaffected peers, individuals born with isolated oral cleft did not have lower socioeconomic status as adults, nor lower chances of becoming a parent. ${ }^{11}$ This contrasts with what might be expected based on previous reports on low educational attainment and its adverse effects on a number of physical and mental health outcomes in addition to socioeconomic status. ${ }^{12}$ A study from Sweden reported lower academic attainment across all cleft groups compared with the general population, ${ }^{13}$ whereas a study from Denmark reported lower grades only for isolated CPO. ${ }^{14}$

In Norway, a uniform public school system makes great efforts to optimise chances of normal development. The clinical treatment of oral clefts is given by multidisciplinary teams which are centralised in two treatment centres. A centralised treatment service has been shown to improve functional outcomes related to clefting. ${ }^{15}$ It also enables large and representative samples, which is a central element of high-quality research. We, therefore, aimed to assess school grades of individuals born with isolated oral cleft in Norway. Analyses of cleft types (CLO, CLP and CPO) were performed to identify any groups that may benefit from additional support. Sex differences in school performance and the effect of cleft laterality were also examined. The identification of isolated clefts is not a trivial task ${ }^{16}$ but is largely facilitated through comprehensive Norwegian registry data. These data also allow for adjustment for several potential confounder variables.

\section{METHODS}

We established a cohort from mandatory, national registries covering all children born in Norway between 1986 and 1992, a total of 404212 children (figure 1). The Norwegian national identity number was used by all registries and facilitated accurate record linkage.

The Medical Birth Registry of Norway ${ }^{17}$ has registered information on all births in Norway since 1967. Our analyses were based on information on congenital malformations and syndromes, parity, maternal age and mother's marital status.

Cleft cases were identified using clinical data with national coverage. In Norway, treatment of oral clefts is carried out at one of two national treatment centres (Haukeland University Hospital, Bergen and Oslo University Hospital, Rikshospitalet, Oslo). Patients who died before referral to surgery were not included in the clinical files. Altogether, 845 children born with oral clefts in the period 1986-1992 were referred for treatment. Follow-up details are provided in figure 1.

We aimed to isolate the impact of the cleft and its treatment from the effects of accompanying syndromes or more severe conditions. Individuals with congenital
Original cohort from Medical Birth Registry of Norway: 404,212 children born 1986-1992

- Cleft cases referred for surgery: 845 (CLO 237; CLP 290; CPO 318)

- Unaffected of clefts: 403,367

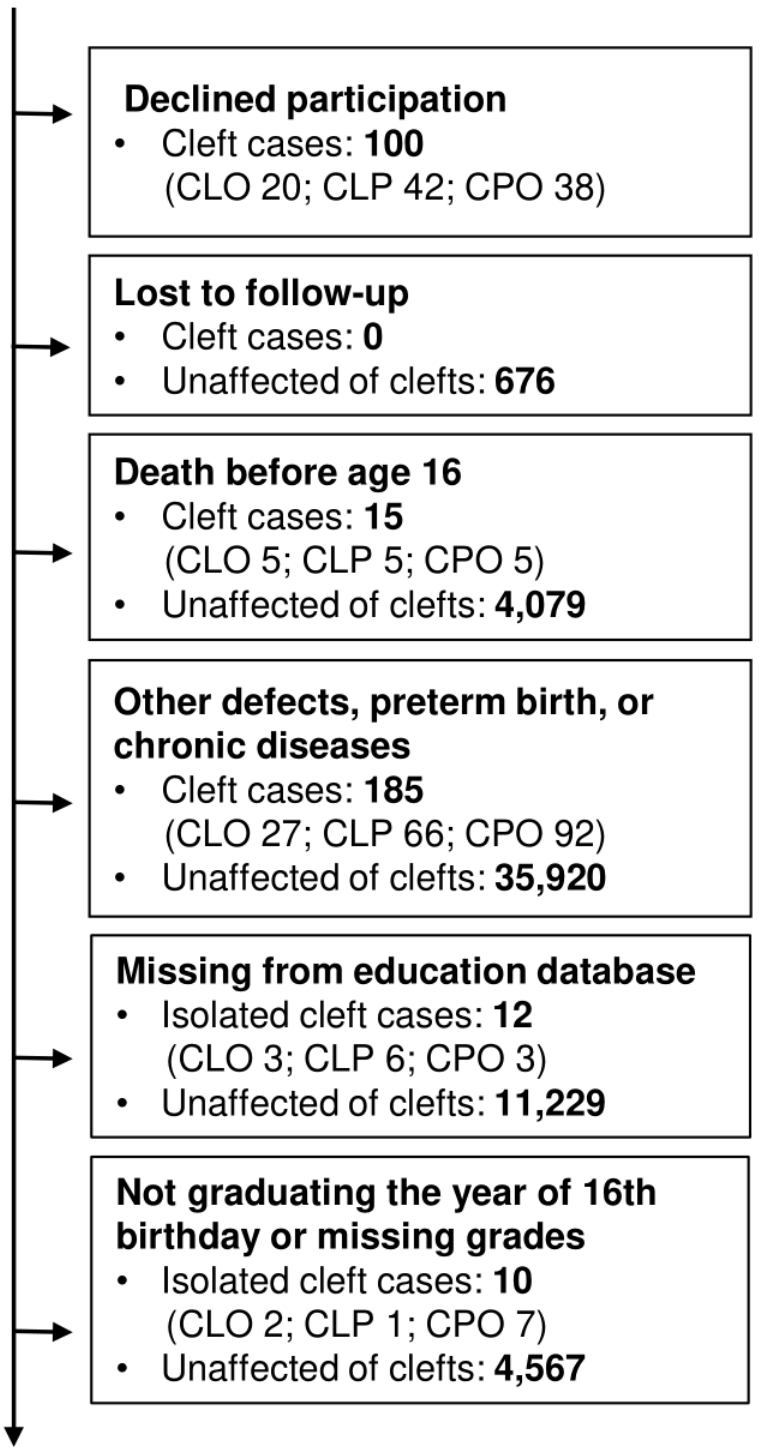

Study cohort with 347,419 individuals

- Isolated cleft cases: $\mathbf{5 2 3}$ (CLO 180; CLP 170; CPO 173)

- Reference group without clefts: $\mathbf{3 4 6 , 8 9 6}$

Figure 1 Details of the identification and follow-up of the cohort. CLO, cleft lip only; CLP, cleft palate; CPO, cleft palate only.

anomalies other than clefts were, therefore, excluded, as well as those born prior to 28 completed weeks of gestation. We also excluded individuals who received financial benefits for expenses due to chronic medical conditions. ${ }^{18}$ Financial benefits are not granted due to the cleft itself and would therefore indicate the 
presence of a separate or accompanying chronic medical condition.

The National Education Database ${ }^{19}$ was the main source of outcome data for the cohort. Before 1997, 9 years of primary schooling was compulsory for all children in Norway from the year they turned 7. Since then, 10 years of primary schooling has been compulsory from the year they turn 6 . We had access to the final grades of pupils graduating in the period 20022008. The vast majority graduate from middle school the year they turn 16, and individuals graduating before or after the year they turned 16 were excluded from the study cohort. The National Education Database also provided data on parents' educational level at the time when cohort members were 16 years old.

A six-level grade scale was used throughout the study period, where 1 is the lowest grade and 6 the highest. Grade point averages (GPAs) were calculated by summing all numerical grades, including exams, and then dividing by the number of grades. In addition to the GPA, we studied grades in four specific subjects-Norwegian (written and oral), Mathematics, English (written and oral) and Physical Education-in line with the main outcome measures of Persson et $a l .^{13}$

Individuals referred for treatment for oral clefts were invited to participate in the study and had the opportunity to withdraw at any time. Data were deidentified and stored on a secure server. The authors are not able to share data obtained from the national registries.

\section{Patient and public involvement}

Patients or the public were not involved in the design, conduct, reporting or dissemination plans of this study.

\section{Statistical methods}

Our main outcome variable was GPA, and kernel density plots were used as a descriptive tool to display the unadjusted GPA distribution of individuals in each cleft group and the reference group of unaffected individuals. We used multiple linear regression to estimate differences in GPA between groups as well as differences in mean grades for each specific subject. Logistic regression models were used to estimate differences in proportions of particularly low or high grades (grades 1 or 2 vs 3 or 4 , and grades 5 or 6 vs 3 or 4 ) (online supplemental analyses). The combination of the linear and logistic regression models makes it possible to detect a general shift in mean grades between groups, as well as differences that are more pronounced for high or low grades.

All analyses were adjusted for sex, maternal age, parity, mother's relationship status and parent's highest level of education at the time when study participants were 16 years old. All covariates were grouped according to the categories shown in table 1, except for maternal age, which was included as a continuous variable. To account for correlation between maternal siblings, we clustered on the mother to obtain robust variance estimates.

We performed additional linear regression analyses of the GPA separately for males and females. For unilateral cleft lip, we also compared the GPA between right-sided and left-sided clefts. Finally, we repeated the main analysis but did not exclude individuals that had other birth defects or chronic conditions.

The logistic regression analyses were also repeated using siblings as reference. These matched and fixed effect analyses with conditional logistic regression aim to adjust for unobserved confounders that are shared between siblings, and the analyses were further adjusted for sex, parity and maternal age.

The statistical analyses were performed with STATA/IC V.15 (StataCorp) and R V.3.2.2 (https://cran.r-project. org). Our conclusions are mainly based on estimated differences and their uncertainty. No attempts were made to adjust for multiple comparisons.

\section{RESULTS}

Characteristics of our study cohort are shown in table 1 . More males than females were born with CLO and CLP, and more females than males were born with CPO. Figure 2 illustrates the smoothed distributions of observed GPA for all cleft groups combined, for each cleft group individually, as well as for the reference group. The mean GPA was 3.98 for CLO, 3.84 for CLP, 3.81 for CPO and 3.99 for the reference group.

Multiple regression analyses showed little evidence of differences between CLO and the reference (figure 3). Point estimates of mean grades were higher for CLO than the reference for the GPA as well as for all specific subjects (adjusted GPA differences with 95\% CIs: 0.06 ( -0.04 to $0.16)$ ). CLP was also similar to the reference (GPA difference: -0.08 ( -0.19 to 0.03$)$, with no apparent differences except for a lower mean grade in Physical education (grade difference: -0.18 (-0.32 to -0.05)). CPO had lower GPA than the reference (GPA difference: $-0.18(-0.28$ to $-0.08)$ ). This group also had lower grades for all subjects, except for physical education. Note, however, that the differences were small in all analyses. As a comparison, the marginally lower GPA of 0.18 corresponds to approximately half of the observed difference between females and males in the reference group (GPA difference: 0.38 ).

Logistic regression analyses, including those with siblings as the reference, confirmed the overall impression (see online supplemental tables 1 and 2). For CPO, however, the point estimate for the OR for low GPA was reduced from 1.61 to 0.88 when siblings were used as the comparison.

Like other studies, we also pooled all three cleft groups into one category consisting of any type of cleft ('any cleft'). Across all subjects, there were no apparent differences in mean grades, except for a small decrease in GPA (GPA difference: -0.06 (95\% CI -0.12 to -0.004$)$ ) and 
Table 1 Characteristics of study cohort

\begin{tabular}{|c|c|c|c|c|c|}
\hline & Any cleft & CLO & CLP & CPO & Reference \\
\hline & $n=523$ & $n=180$ & $n=170$ & $n=173$ & $n=346896$ \\
\hline Males, n (\%) & $316(60.4)$ & $123(68.3)$ & $121(71.2)$ & $72(41.6)$ & $175133(50.5)$ \\
\hline \multicolumn{6}{|l|}{ Parity, n (\%) } \\
\hline 0 (first born) & $211(40.3)$ & $74(41.1)$ & $71(41.8)$ & $66(38.2)$ & $149056(43.0)$ \\
\hline 3 & $34(6.5)$ & $9(5.0)$ & $14(8.2)$ & $11(6.4)$ & $14474(4.2)$ \\
\hline$\geq 4$ & $11(2.1)$ & $5(2.8)$ & $1(0.6)$ & $5(2.9)$ & $5372(1.6)$ \\
\hline \multicolumn{6}{|l|}{ Mothers' relationship status, n (\%) } \\
\hline Married & $322(62.0)$ & $117(65.0)$ & $104(61.9)$ & $101(59.1)$ & $223172(64.5)$ \\
\hline \multicolumn{6}{|l|}{ Parents' highest education, $\mathrm{n}(\%)$} \\
\hline Master or PhD & $50(9.6)$ & $16(8.9)$ & $19(11.2)$ & $15(8.7)$ & $37124(10.7)$ \\
\hline Bachelor & $146(27.9)$ & $57(31.7)$ & $47(27.7)$ & $42(24.3)$ & $107986(31.2)$ \\
\hline High school & $280(53.5)$ & $92(51.1)$ & $88(51.8)$ & $100(57.8)$ & $166142(48.0)$ \\
\hline Compulsory school & $47(9.0)$ & $15(8.3)$ & $16(9.4)$ & $16(9.3)$ & $35223(10.2)$ \\
\hline \multicolumn{6}{|l|}{ Parents' immigrant background, n (\%) } \\
\hline Both parents born in Norway & $488(93.3)$ & $166(92.2)$ & $156(91.8)$ & $166(96.0)$ & 315607 (91.0) \\
\hline Both parents foreign-born & $11(2.1)$ & $5(2.8)$ & $4(2.4)$ & $2(1.2)$ & $9503(2.7)$ \\
\hline Only one parent born in Norway & $24(4.6)$ & $9(5.0)$ & $10(5.9)$ & $5(2.9)$ & $21786(6.3)$ \\
\hline
\end{tabular}

*Missing information: Mother's relationship status: 738 subjects missing from reference group, 2 from CPO, 2 from CLP; Parents' highest education: 421 subjects missing from reference group.

CLO, cleft lip only; CLP, cleft palate; CPO, cleft palate only.

Oral English (grade difference: $-0.09(95 \% \mathrm{CI}-0.17$ to $-0.007)$ ) (figure 3).

In the sex-stratified analyses, the GPA for females with CLO was higher than for females in the reference group

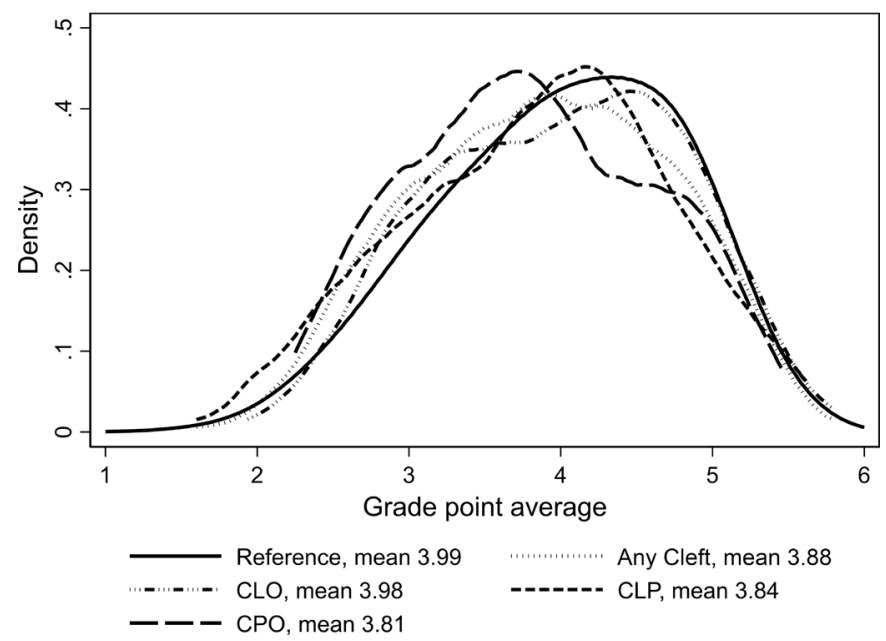

Figure 2 Kernel density plot of the observed grade point average distribution of individuals born within each cleft group and the reference group of unaffected individuals. CLO, cleft lip only; CLP, cleft palate; CPO, cleft palate only.
(GPA difference: 0.19 (0.013 to 0.36$)$ ), whereas the GPA for males with $\mathrm{CPO}$ was lower than for males in the reference group (GPA difference: -0.25 (95\% CI -0.40 to -0.11)) (online supplemental Figure 1). Males with CLO and CLP and females with CPO and CLP had similar GPAs as their references.

For the subgroups of CLO and CLP with unilateral cleft lip, we found little evidence of a difference in GPA between right-sided and left-sided clefts (online supplemental figure 2). We also repeated the main GPA analysis while including the cases with identified syndromes or chronic medical conditions that we originally excluded. The results are in general agreement with those of the isolated clefts, but with a small shift towards more negative values (online supplemental figure 3 ).

\section{DISCUSSION}

Children born in Norway with isolated CLO or CLP had similar grades as their non-affected peers when graduating from middle school. The CPO group had slightly lower grades, corresponding to less than half of the observed difference between females and males in unaffected individuals. This is consistent with a study from 
Any Cleft

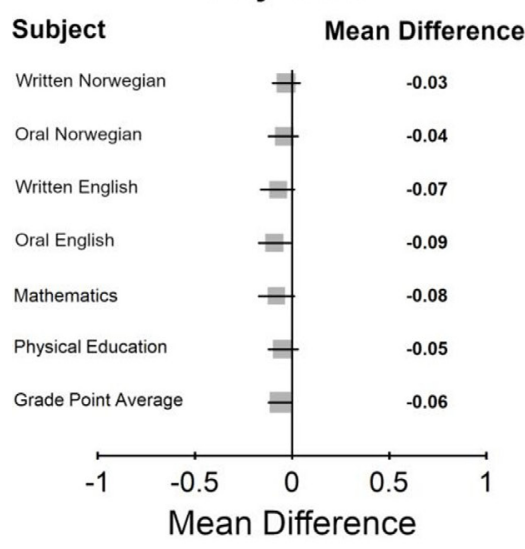

CLP

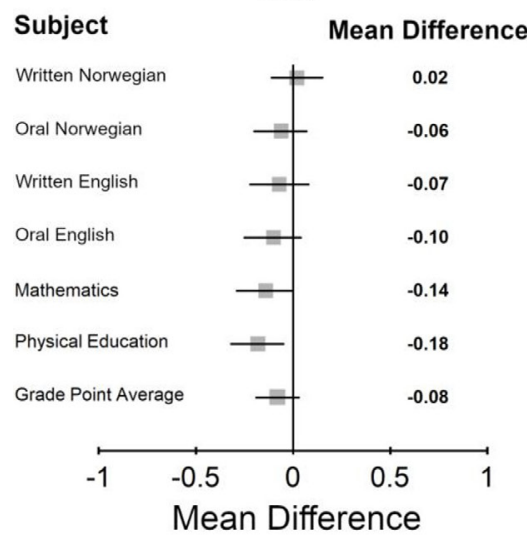

CLO

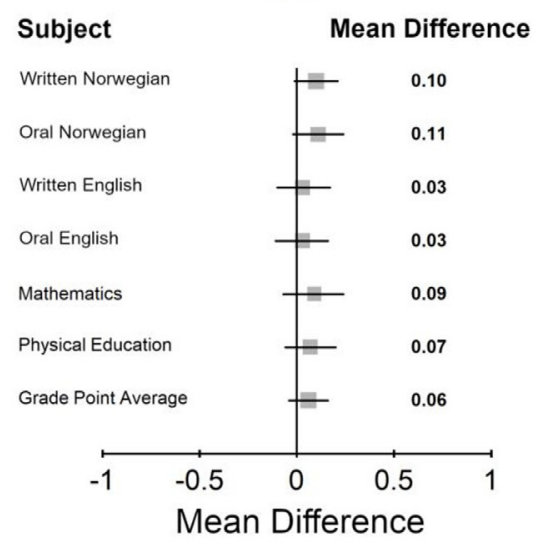

\section{CPO}

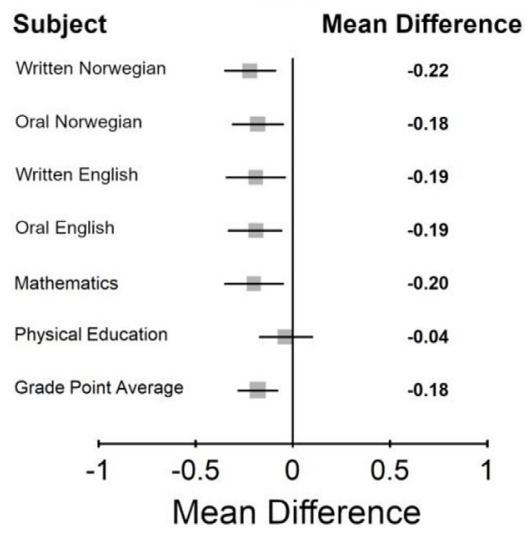

Figure 3 Difference in means comparing each cleft group with the reference group from linear regression models for the grade point average and specific subject grades. Horizontal bars represent $95 \% \mathrm{Cls}$. Analyses were adjusted for sex, maternal age, parity, mother's relationship status and parent's highest level of education at the time when study participants were 16 years old. CLO, cleft lip only; CLP, cleft palate; CPO, cleft palate only.

Denmark, ${ }^{14}$ which also found lower grades only for CPO, but apparently different from population-based studies from England, Sweden and Iowa, where lower school grades were reported across all cleft groups. 51320

Apparent differences between studies may partly be explained by limited statistical power, methodological inconsistencies and differences in data quality and content. Our study was smaller than the studies from Sweden and England but comparable to the studies from Iowa and Denmark. In our study, we adjusted for potential confounding variables such as sex and parents' education. Consistent with previous findings, ${ }^{21}$ there was a higher proportion of males with CLO and with CLP in our data (see table 1). Since males generally attain lower grades than females, confounding by sex may partly explain the lower grades for CLO and CLP reported from Sweden (the authors do not mention adjustment for this variable in their analysis of GPA). ${ }^{13}$ The study from England ${ }^{5}$ adjusted for sex but not for parent's education, while the studies from Iowa ${ }^{20}$ and Denmark ${ }^{14}$ adjusted for both sex and parents' education. The study from England ${ }^{5}$ reported academic achievement at age 5, whereas our current study was based on school grades at age 16 .
Another methodological issue is the process of exclusion of cases with non-isolated clefts. A follow-up study from Norway found that $39.5 \%$ of oral cleft cases had other accompanying medical or psychological conditions that could affect cognitive development and learning, suggesting that it might be difficult to establish clear criteria to define the group of isolated cleft cases. ${ }^{22}$ Our study used available data from several registries but may still have failed to exclude some non-isolated cases. This may have biased our estimates for the CPO group, which is known to have a higher proportion of cases with accompanying defects than the CLO and CLP groups. ${ }^{16}$

Unlike a study of unilateral cleft lip from Iowa, ${ }^{10}$ we found no evidence that a child with left-sided cleft lip was more likely to perform worse in school compared with a child with right-sided cleft lip. However, the sample size is limited, and more studies are needed to examine the effect of cleft laterality. The tendency in England and Sweden that grades of females with clefts were more negatively affected than grades of males with clefts ${ }^{69}$ was not replicated.

The logistic regression analyses investigating low or high grades confirmed the overall impression from the 
linear regression analyses. Furthermore, there were only marginal differences between cleft cases and their siblings. This is in agreement with a study from Iowa, which also showed that children born with oral clefts performed similarly to their siblings. ${ }^{23}$ Sibling analyses are assumed to adjust for more of the unobserved confounding and may provide better estimates of the impact of an oral cleft itself. The study from Iowa identified lower grades for all cleft groups when compared with reference groups other than their siblings. Thus, the authors suggest that even the grades of siblings of affected children may be reduced due to a common underlying vulnerability. Few large population studies have investigated this question, and future research is needed to differentiate the impact of a cleft from other background factors.

A Mendelian randomisation study showed that a genetic predisposition to non-syndromic CLO or CLP did not predispose to lower educational attainment or lower IQ. ${ }^{24}$ This supports the finding that children with an isolated CLO or CLP have prospects of school results similar to other children, provided they are given good clinical treatment and educational follow-up. Our study was also consistent with the study by Berg et al, ${ }^{11}$ showing that CLO and CLP performed well on social outcomes.

Oral health, hearing and speech difficulties are directly related to the cleft itself ${ }^{25-29}$ and have been shown to affect the educational attainment of individuals born with isolated cleft. ${ }^{6}$ Atypical brain development ${ }^{3031}$ and exposure to anaesthesia during surgical treatment ${ }^{14}$ have also been suggested to influence their academic achievement, although observations are uncertain due to small sample sizes. Indirect effects such as school absence have been found to affect educational attainment of children born with cleft in England, ${ }^{7}$ whereas results from Western Australia showed that absence from school did not differentially disadvantage these children. ${ }^{32}$ Low self-confidence has also been found to affect educational attainment for cleft children, ${ }^{6}$ and appearance, social acceptance and interactions, bullying and poor integration in the school system may also play a role. ${ }^{24}{ }^{33-36}$ Several of these factors could be modifiable and thus important to identify.

In Norway, the clinical treatment of oral cleft is centralised in two treatment centres, where multidisciplinary teams follow the children closely from birth throughout adolescence. The Norwegian school system is based on public schools, and the proportion of private educational institutions is negligible. Moreover, speech and language therapy for children with cleft palate is defined as a special educational measure and required by Norwegian law. Speech therapists follow the individual speech and language development of children with cleft palate at no cost for the families, starting at the time of palate closure. The speech therapist acts as a liaison between the family, school system and treatment team, and hence also ensures additional educational follow-up when necessary. These efforts may partly explain why children born with oral cleft in Norway seem to perform well in school. Unfortunately, data were not available in this study to identify associations between functional outcomes in children born with cleft and educational achievement.

Similarities in healthcare and educational systems in Scandinavian countries may explain the consistency between the results from our study and the study from Denmark. ${ }^{14}$ Although Persson et al ${ }^{13}$ conclude that adolescents born with an oral cleft in Sweden experience significant deficits in their educational achievements in compulsory school, the difference reported in GPA is small, and their conclusion does not take multiple comparisons into account. The poor educational attainment of cleft children reported from England ${ }^{5}$ and Iowa ${ }^{20}$ may also suggest that efforts invested to help children born with oral cleft in Scandinavian countries are effective, but it is difficult to make direct comparisons between societies with different health and school systems, and different sources of data.

Although our sample size was not as large as those from England ${ }^{5}$ and Sweden, ${ }^{13}$ we used population-based data with an assumed high degree of completeness, and we had access to extensive information on congenital anomalies, chronic medical conditions and social background variables. We were, however, not able to adjust for maternal lifestyle factors such as smoking and alcohol consumption during pregnancy. It is possible that the high ascertainment of accompanying medical problems for CLO contributed to an apparently higher achievement compared with the reference. When we included non-isolated clefts, all cleft groups had, as expected, lower estimated GPA. For CPO, where syndromes are known to be more frequent, incomplete identification of cases with syndromes, severe learning disabilities or other congenital problems affecting cognitive development and learning may have contributed to an underestimation of achievements.

In Norway, individuals born with isolated CLO or CLP did not have lower average school grades when graduating from middle school. Individuals born with isolated CPO had marginally lower grades. This suggests that the universal treatment and educational systems in Norway may have a beneficial effect on school performance for children born with isolated oral clefts. The relative contributions of potentially critical components of healthcare and educational programmes, including stimulation of speech and language development, could not be evaluated by this study. More research is needed to assess the individual effects of such measures.

Acknowledgements The Norwegian Quality Registry of Cleft Lip and Palate facilitated the work. The authors gratefully thank all the participants.

Contributors MG conceptualised the study, performed the main analyses, drafted the initial manuscript. RTL conceptualised the study, analysed the data, drafted the initial manuscript. ØAH conceptualised the study, analysed the data, revised the manuscript. EB conceptualised the study and revised the manuscript. KBF conceptualised the study and revised the manuscript. ÅS initiated and conceptualised the study, recruited patients and obtained data, revised the manuscript. 
Funding This work was supported by Helse Vest, project number 911381 , and by the Research Council of Norway through its Centres of Excellence funding scheme, project number 262700 .

Competing interests None declared.

Patient consent for publication Not required.

Ethics approval The study was approved by the Regional Committees for Medical and Health Research Ethics (Ref. 2010/1098) and the Norwegian Data Protection Authority.

Provenance and peer review Not commissioned; externally peer reviewed.

Data availability statement Data may be obtained from a third party and are not publicly available. The data are not publicly available but could be made available through the application portal helsedata.no, contact with the clinical registry "Norsk kvalitetsregister for leppe-kjeve-ganespalte" and by contacting Statistics Norway.

Supplemental material This content has been supplied by the author(s). It has not been vetted by BMJ Publishing Group Limited (BMJ) and may not have been peer-reviewed. Any opinions or recommendations discussed are solely those of the author(s) and are not endorsed by BMJ. BMJ disclaims all liability and responsibility arising from any reliance placed on the content. Where the content includes any translated material, BMJ does not warrant the accuracy and reliability of the translations (including but not limited to local regulations, clinical guidelines, terminology, drug names and drug dosages), and is not responsible for any error and/or omissions arising from translation and adaptation or otherwise.

Open access This is an open access article distributed in accordance with the Creative Commons Attribution Non Commercial (CC BY-NC 4.0) license, which permits others to distribute, remix, adapt, build upon this work non-commercially, and license their derivative works on different terms, provided the original work is properly cited, appropriate credit is given, any changes made indicated, and the use is non-commercial. See: http://creativecommons.org/licenses/by-nc/4.0/.

ORCID iD

Rolv Terje Lie http://orcid.org/0000-0001-6287-4051

\section{REFERENCES}

1 Mossey PA, Little J, Munger RG, et al. Cleft lip and palate. Lancet 2009;374:1773-85.

2 Dixon MJ, Marazita ML, Beaty TH, et al. Cleft lip and palate: understanding genetic and environmental influences. Nat Rev Genet 2011;12:167-78.

3 Feragen KB, Rumsey N, Heliövaara A, et al. Scandcleft randomised trials of primary surgery for unilateral cleft lip and palate: 9. parental report of social and emotional experiences related to their 5-year-old child's cleft diagnosis. J Plast Surg Hand Surg 2017;51:73-80.

4 Gallagher ER, Collett BR. Neurodevelopmental and academic outcomes in children with orofacial clefts: a systematic review. Pediatrics 2019;144:e20184027.

5 Fitzsimons KJ, Copley LP, Setakis E, et al. Early academic achievement in children with isolated clefts: a population-based study in England. Arch Dis Child 2018;103:356-62.

6 Grewal SS, Ponduri S, Leary SD, et al. Educational attainment of children born with unilateral cleft lip and palate in the United Kingdom. Cleft Palate Craniofac J 2021;58:587-96.

7 Fitzsimons KJ, Deacon SA, Copley LP, et al. School absence and achievement in children with isolated orofacial clefts. Arch Dis Child 2021;106:154-9.

8 Wehby GL, Collett BR, Barron S, et al. Children with oral clefts are at greater risk for persistent low achievement in school than classmates. Arch Dis Child 2015;100:1148-54.

9 Persson M, Becker M, Conrad AL, et al. Female and male differences in academic achievement in individuals with cleft: a populationbased register study. Cleft Palate Craniofac J 2018;55:196-203.

10 Gallagher ER, Collett BR, Barron S, et al. Laterality of oral clefts and academic achievement. Pediatrics 2017;139:e20162662.

11 Berg E, Sivertsen Å, Ariansen AMS, et al. Socio-economic status and reproduction among adults born with an oral cleft: a populationbased cohort study in Norway. PLoS One 2016;11:e0162196.
12 Davies NM, Dickson M, Davey Smith G, et al. The causal effects of education on health outcomes in the UK Biobank. Nat Hum Behav 2018;2:117-25.

13 Persson M, Becker M, Svensson H. Academic achievement in individuals with cleft: a population-based register study. Cleft Palate Craniofac J 2012;49:153-9.

14 Clausen NG, Pedersen DA, Pedersen JK, et al. Oral clefts and academic performance in adolescence: the impact of anesthesiarelated neurotoxicity, timing of surgery, and type of oral clefts. Cleft Palate Craniofac J 2017;54:371-80.

15 Ness AR, Wills AR, Waylen A, et al. Closing the loop on centralization of cleft care in the United Kingdom. Cleft Palate Craniofac $J$ 2018;55:248-51.

16 Wyszynski DF, Sárközi A, Czeizel AE. Oral clefts with associated anomalies: methodological issues. Cleft Palate Craniofac $J$ 2006;43:1-6.

17 Irgens LM. The Medical Birth Registry of Norway. Epidemiological research and surveillance throughout 30 years. Acta Obstet Gynecol Scand 2000;79:435-9.

18 Norwegian Ministry of Labour and Social Affairs. The Norwegian social insurance scheme, 2020. Available: https://www.regjeringen. no/contentassets/03b0e088c8f44a8793ed0c0781556b11/a-0008-ethe-norwegian-social-insurance-scheme-2020.pdf

19 The National Education Database. Statistics Norway. Available: https://www.ssb.no/data-til-forskning/utlan-av-data-til-forskere/ variabellister/utdanning/

20 Wehby GL, Collet B, Barron S, et al. Academic achievement of children and adolescents with oral clefts. Pediatrics 2014;133:785-92.

21 Harville EW, Wilcox AJ, Lie RT, et al. Cleft lip and palate versus cleft lip only: are they distinct defects? Am J Epidemiol 2005;162:448-53.

22 Feragen KB, Stock NM. When there is more than a cleft: psychological adjustment when a cleft is associated with an additional condition. Cleft Palate Craniofac J 2014;51:5-14.

23 Collett BR, Wehby GL, Barron S, et al. Academic achievement in children with oral clefts versus unaffected siblings. J Pediatr Psychol 2014;39:743-51.

24 Dardani C, Howe LJ, Mukhopadhyay N, et al. Cleft lip/palate and educational attainment: cause, consequence or correlation? A Mendelian randomization study. Int J Epidemiol 2020;49:1282-93.

25 Smallridge J, Hall AJ, Chorbachi R, et al. Functional outcomes in the cleft care UK study-Part 3: oral health and audiology. Orthod Craniofac Res 2015;18:25-35.

26 Skuladottir H, Sivertsen A, Assmus J, et al. Hearing outcomes in patients with cleft lip/palate. Cleft Palate Craniofac J 2015;52:23-31.

27 Knight J, Cassell CH, Meyer RE, et al. Academic outcomes of children with isolated orofacial clefts compared with children without a major birth defect. Cleft Palate Craniofac J 2015;52:259-68.

28 Sell D, Mildinhall S, Albery L, et al. The cleft care UK study. Part 4: perceptual speech outcomes. Orthod Craniofac Res 2015;18:36-46.

29 Feragen KB, Aukner R, Særvold TK, et al. Speech, language, and reading skills in 10-year-old children with palatal clefts: the impact of additional conditions. J Commun Disord 2017;66:1-12.

30 Adamson CL, Anderson VA, Nopoulos P, et al. Regional brain morphometric characteristics of nonsyndromic cleft lip and palate. Dev Neurosci 2014;36:490-8.

31 Nopoulos P, Berg S, VanDemark D, et al. Cognitive dysfunction in adult males with non-syndromic clefts of the lip and/or palate. Neuropsychologia 2002;40:2178-84.

32 Bell J, Raynes-Greenow C, Turner R, et al. School absence and its effect on school performance for children born with orofacial clefts. Birth Defects Res 2017;109:1048-56.

33 Feragen KB, Borge AlH. Peer harassment and satisfaction with appearance in children with and without a facial difference. Body Image 2010;7:97-105.

34 Glener AD, Allori AC, Shammas RL, et al. A population-based exploration of the social implications associated with cleft lip and/or palate. Plast Reconstr Surg Glob Open 2017;5:e1373.

35 Stock NM, Ridley M. Young person and parent perspectives on the impact of cleft lip and/or palate within an educational setting. Cleft Palate Craniofac J 2018;55:607-14.

36 Stock NM, Ridley M, Guest E. Teachers' perspectives on the impact of cleft lip and/or palate during the school years. Cleft Palate Craniofac J 2019;56:204-9. 